\title{
Measurement of Motor Evoked Potential in Acute Ischemic Stroke: Based on Latency, Amplitude, Central Motoric Conduction Time and Resting Motor Threshold
}

\author{
Tugas Ratmono ${ }^{1,2}$, Andi Wijaya ${ }^{1,3,4}$, Cahyono Kaelan ${ }^{5}$, Andi Asadul Islam ${ }^{6}$, Ferry Sandra ${ }^{4,7, *}$ \\ ${ }^{1}$ Postgraduate Program in Clinical Biochemistry, Faculty of Medicine, Hasanuddin University, Jl. Perintis Kemerdekaan Km.10, Makassar, Indonesia \\ ${ }^{2}$ Brain Stimulation Clinic in Cerebrovascular Center of Presidential Hospital, Gatot Soebroto Army Central Hospital, Jl. Abdul Rahman Saleh No. 24, \\ Jakarta, Indonesia \\ ${ }^{3}$ Postgraduate Program in Clinical Pharmacy, Padjadjaran University, Jl. Eijkman No.38, Bandung, Indonesia \\ ${ }^{4}$ Prodia Clinical Laboratory, Prodia Tower, Jl. Kramat Raya No.150, Jakarta, Indonesia \\ ${ }^{5}$ Department of Anatomic Pathology, Faculty of Medicine, Hassanuddin University, Jl. Perintis Kemerdekaan Km.10, Makassar, Indonesia \\ ${ }^{6}$ Department of Neurosurgery, Faculty of Medicine, Hassanuddin University, Jl. Perintis Kemerdekaan Km.10, Makassar, Indonesia \\ ${ }^{7}$ Department of Biochemistry and Molecular Biology, Faculty of Dentistry, Trisakti University, Jl. Kyai Tapa No.260, Jakarta, Indonesia \\ *Corresponding author. E-mail: ferrysandra@yahoo.com
}

Received date: Apr 25, 2016; Revised date: Jul 22, 2016; Accepted date: Jul 27, 2016

\section{Abstract}

$\mathrm{B}$ ACKGROUND: After stroke, there are dynamic changes of motor evoked potential (MEP), including latency, amplitude, central motoric conduction time $(\mathrm{CMCT})$ and resting motor threshold (RMT) in cerebral. However, latency, CMCT, amplitude and RMT have not been clearly shown in acute ischemic stroke patients with motoric function impairment based on Modified Motoric Research Council Scale (MRCs).

METHODS: Patients with motoric function impairment after acute ischemic stroke were recruited, scored based on MRCs and grouped. Latency, amplitude, CMCT and RMT (\% intensity) was measured using transcranial magnetic stimulation (TMS). Latency, amplitude, CMCT and RMT of subjects based on affected hemisphere (AH) and unaffected hemisphere (UH); stroke onset; and motoric severity; were analyzed and compared statistically.
RESULTS: Thirty-seven subjects with completeassessments were selected. Results of MEP size measurement between $\mathrm{AH}$ and $\mathrm{UH}$ showed that latency, amplitude, CMCT and RMT of AH and UH were significantly different $(p<0.05)$. In accordance to $\mathrm{AH}$ and $\mathrm{UH}$ results, latency, amplitude, CMCT and RMT of mild, moderate and severe groups based on motoric severity, showed that latency and CMCT were prolonged, RMT was increased, while amplitude was decreased along with severity increment. The amplitude and RMT among the groups were significantly different with $p=0.034$ and $p=0.029$, respectively.

CONCLUSION: MEP size measurement including latency, amplitude, CMCT and RMT have significant different in $\mathrm{AH}$ and $\mathrm{UH}$. In addition, amplitude and RMT were significantly different in MRCs groups, therefore the MEP size measurement could be suggested as prognostic tool.

KEYWORDS: MEP, latency, amplitude, CMCT, RMT

Indones Biomed J. 2016; 8(3): 157-60

\section{Introduction}

Stroke is a disease that leads to death and causes long-term disability. At five years after stroke, the survival rate is about $40 \%$, and about half of survivors are disabled and dependent.(1) When the cerebral blood flow (CBF) into brain tissue was low, the cascade of ischemia will go on. This will lead to infarction with cell death in damage core tissue and decrease of brain functions including motoric function.(2) In addition, brain activity will be also decreased in the ipsilateral of infarct and increased in the contralateral.(3) 
The brain activity can be measured by motor evoked potential (MEP), which is correlated with inhibition and excitation of neural cell during the acute injuries process of the ischemic stroke. After stroke, there are dynamic changes of MEP including latency, amplitude, central motoric conduction time (CMCT) and resting motor threshold (RMT) in cerebral.(4) Since neuron was injured, neuronal activity can be decreased. The neural activity will cause MEP size variability based on severity of infarction and can be measured by transcranial magnetic stimulation (TMS) machine. Neuro-physiologically, prolonged latency and CMCT, decrease of amplitude and increase of RMT were detected after stroke. $(3,4)$

However, to our knowledge, latency, CMCT, amplitude and RMT have not been clearly shown in acute ischemic stroke patients with motoric function impairment based on Modified Motoric Research Council Scale (MRCs).(5) Therefore current retrospective study was conducted using TMS in patients with motoric function impairment after acute ischemic stroke with parameter of latencies, amplitude, CMCT and RMT.

\section{Methods}

\section{Subject Selection}

Patients with motoric function impairment after acute ischemic stroke were recruited within May-October 2015 from Cerebrovascular Center of Indonesia Army Central Hospital, Jakarta. Selected patients were all having first event of stroke with motoric function impairment for $\leq 14$ days. Severity of motoric function impairment was scored by MRCs on upper limb and grouped into: mild, score: 28-34; moderate, score 21-27; and severe score: $<21$. The normal score of MRCs on the upper limb is 35 .

\section{MEP Size Measurement}

MEP size measure was conducted by using TMS Neurosoft Variant 4 (Neurosoft, Ivanovo, Russia). Big ring coil was placed on vertex and single pulse stimulation was given. Side B of the coil (anticlockwise) was used to stimulate left hemisphere, while side A (clockwise) to stimulate right hemisphere. To measure latency (millisecond/ms), amplitude (millivolt $/ \mathrm{mV}$ ), CMCT (ms) and RMT (\% intensity) of MEP was recorded with stimulation of submaximal threshold $80 \%$ MEP at each side.

\section{Statistical Analysis}

Latency, amplitude, CMCT and RMT of subjects based on affected hemisphere (AH) and unaffected hemisphere (UH); stroke onset; and motoric severity; were analyzed and compared. SPSS for Windows, Version 22.0 was used to evaluate the significant level of $p<0.05$ (SPSS Inc., Armonk, USA).

\section{Results}

Thirty seven subjects with complete assessments were selected. Based on motoric severity, 17 subjects were grouped as mild with mean MRCs score of $28.77 \pm 0.45,8$ subjects were grouped as moderate with mean MRCs score of $23.87 \pm 0.89$ and 12 subjects were grouped as severe with mean MRCs score of $10.50 \pm 1.66$. General characteristic of subjects is shown in Table 1. More males than females were recorded. Based on onset of stroke, subjects were further grouped into subjects with onset of $\leq 7$ days (27 subjects) and 8-14 days (10 subjects). Subjects were then evaluated for each risk factor, including hypertension, diabetes, coronary arterial disease (CAD), dyslipidemia, hypercoagulation, polycythemia and hyperuricemia. Percentages of each risk factor are shown in Table 1.

Table 1. Characteristic of subjects $(n=37)$.

\begin{tabular}{llc}
\hline Variable & $\begin{array}{c}\text { Number of Subject } \\
\text { (mean } \pm \text { SD or \%) }\end{array}$ \\
\hline Age & Male & $28(57.92 \pm 1.52)$ \\
\hline Onset & Female & $9(75.68 \%)$ \\
& $\leq 7$ days & $27(72.97 \%)$ \\
\hline Motoric Severity & Mild & $10(27.03 \%)$ \\
& Moderate & $17(45.95 \%)$ \\
& Severe & $8(21.62 \%)$ \\
\hline Risk Factor & Hypertension & $12(32.43 \%)$ \\
\hline & Diabetes & $25(67.57 \%)$ \\
& CAD & $8(21.62 \%)$ \\
& Dyslipidemia & $27(72.97 \%)$ \\
& Hypercoagulation & $13(35.14 \%)$ \\
& Polycythemia & $1(2.70 \%)$ \\
& Hyperuricemia & $1(2.70 \%)$ \\
\hline
\end{tabular}


Results of MEP size measurement were compared between $\mathrm{AH}$ and $\mathrm{UH}$. All parameters of MEP including latency, amplitude, CMCT and RMT of AH and $\mathrm{UH}$ were significantly different $(p<0.05)$ (Table 2$)$. When the hemisphere was affected, latency and CMCT were prolonged, RMT was increased, while amplitude was decreased. The highest significant result was seen for CMCT with $p=0.000$.

Latency, amplitude, CMCT and RMT of $\leq 7$ and 8-14 days based on onset, were compared. Results of onset in Table 3 showed latency and CMCT were prolonged, RMT and amplitude were increased along with onset period. The CMCT of the $\leq 7$ and 8-14 days were significantly different with $p=0.006$.

Latency, amplitude, CMCT and RMT of mild, moderate and severe groups based on motoric severity, were compared. In accordance to Table 2 for AH and UH results, results of motoric severity in Table 4 showed that latency and CMCT were prolonged, RMT was increased, while amplitude was decreased along with severity increment. The amplitude and RMT among the groups were significantly different with $p=0.034$ and $p=0.029$, respectively.

\section{Discussion}

In our study, we found that latency, amplitude, CMCT and RMT were significantly different in $\mathrm{AH}$ and $\mathrm{UH}$ of subjects. These results showed that our measurement was in accordance to previous report (4), suggesting that the neuronal activities were significantly decreased in AH. Hence, we propose latency, amplitude, CMCT and RMT can be good measurements to recognize affected site. In addition, we found that amplitude and RMT were significantly different in MRCs groups, suggesting that

Table 2. Means of latency, amplitude, CMCT and RMT in AH and UH of subjects.

\begin{tabular}{lccc}
\hline \multicolumn{1}{c}{ Variable } & $\begin{array}{c}\text { AH } \\
(\mathbf{m e a n} \pm \text { SE) }\end{array}$ & $\begin{array}{c}\text { UH } \\
(\text { mean } \pm \text { SE) }\end{array}$ & $\boldsymbol{p}$ value* \\
\hline Latency $(\mathrm{ms})$ & $24.17 \pm 0.68$ & $21.96 \pm 0.52$ & 0.004 \\
Amplitude $(\mathrm{mV})$ & $0.97 \pm 0.26$ & $1.68 \pm 0.20$ & 0.001 \\
CMCT $(\mathrm{ms})$ & $11.01 \pm 0.93$ & $7.69 \pm 0.20$ & 0.000 \\
RMT $(\%$ intensity) & $70.54 \pm 2.44$ & $62.57 \pm 1.87$ & 0.013 \\
\hline *Mann Whitney Test & & &
\end{tabular}

Table 3. Means of latency, amplitude, CMCT and RMT in each group based on onset.

\begin{tabular}{lccc}
\hline \multirow{2}{*}{ Variable } & \multicolumn{2}{c}{ Onset } & \\
\cline { 2 - 3 } & $\begin{array}{c}\leq 7 \text { days } \\
(\text { mean } \pm \text { SE) }\end{array}$ & $\begin{array}{c}\text { 8-14 days } \\
(\text { mean } \pm \text { SE) }\end{array}$ & p value \\
\hline Latency $(\mathrm{ms})$ & $23.98 \pm 0.61$ & $26.89 \pm 2.08$ & $0.075^{*}$ \\
Amplitude $(\mathrm{mV})$ & $0.74 \pm 0.36$ & $0.81 \pm 0.39$ & $0.347^{*}$ \\
CMCT $(\mathrm{ms})$ & $9.28 \pm 0.53$ & $15.44 \pm 2.84$ & $0.006^{*}$ \\
RMT $(\%$ intensity) & $69.00 \pm 2.77$ & $75.50 \pm 5.96$ & $0.626^{* *}$ \\
\hline *Mann Whitney Test **Independent Samples T Test &
\end{tabular}

Table 4. Means of latency, amplitude, CMCT and RMT in each group based on motoric severity.

\begin{tabular}{|c|c|c|c|c|}
\hline \multirow[b]{2}{*}{ Variable } & \multicolumn{3}{|c|}{ MRCs Group } & \multirow[b]{2}{*}{$p$ value } \\
\hline & $\begin{array}{c}\text { Mild } \\
(\operatorname{mean} \pm \text { SE })\end{array}$ & $\begin{array}{c}\text { Moderate } \\
(\operatorname{mean} \pm \text { SE) }\end{array}$ & $\begin{array}{c}\text { Severe } \\
(\operatorname{mean} \pm \text { SE })\end{array}$ & \\
\hline Latency (ms) & $23.74 \pm 0.56$ & $24.04 \pm 0.84$ & $24.87 \pm 1.93$ & $0.697 *$ \\
\hline Amplitude (mV) & $1.29 \pm 0.46$ & $0.96 \pm 0.47$ & $0.54 \pm 0.33$ & $0.034 *$ \\
\hline CMCT (ms) & $10.03 \pm 0.67$ & $9.96 \pm 0.47$ & $13.12 \pm 2.59$ & $0.303 * *$ \\
\hline RMT (\% intensity) & $64.71 \pm 3.28$ & $70.00 \pm 4.23$ & $79.17 \pm 4.39$ & $0.029 * *$ \\
\hline
\end{tabular}


these measurements can also be sensitive enough to differentiate motoric severity. Although latency and CMCT were not significantly different among the groups, it showed prolonged results. When results of MRCs groups with different motoric severities were compared with UH, latency and CMCT were prolonged, amplitude was decreased and RMT was increased. These results showed consistency of MEP size measurement for acute ischemic stroke.

Based on onset, CMCT of the $\leq 7$ and 8-14 days were significantly different, suggesting that when the onset was prolonged, more conductivity disturbance occurred. In addition, latency was prolonged as well as RMT was increased in 8-14 days onset, although not significant. Amplitude was found insignificantly increased in 8-14 days onset, and when compared to UH, the amplitude of 8-14 days onset was much lower. In regards of risk factor, current results showed that the highest percentage was dyslipidemia. Other study also showed that dyslipidemia was a dominant risk factor of stroke, mostly ischemic stroke.(6) Hypertension, a mostly mentioned risk factor of stroke, was also found in this study as the second highest risk factor.

Brain activity can be described as neuron electricity in the brain tissue.(7) When brain motoric function activity was disturbed caused by stroke infarction, motoric power could be decreased. In long term period, this will lead to motoric disability.(8) Latency, amplitude, CMCT and RMT are important in describing neuronal activities. CMCT and latency are possibly correlated with the integrity of corticospinal pathway conduction.(9) The patients with prolonged CMCT recovered more slowly than those with normal CMCT.(10) Most stroke patients with severe hemiparesis was reported to have absent of CMCT in $\mathrm{AH}$, and only few patients had prolonged CMCT.(10) Amplitude and RMT are the reflection of the neuron cell integrity, suggesting that neuronal cells can activate connected neurons. Low level of amplitude has tendency of motoric severity.(11)

\section{Conclusion}

MEP size measurement including latency, amplitude, CMCT and RMT have significant different in $\mathrm{AH}$ and $\mathrm{UH}$. Therefore this measurement can be useful to detect affected brain. In addition, amplitude and RMT were significantly different in MRCs groups, therefore the MEP size measurement could be suggested as a prognostic tool.

\section{Acknowledgements}

We would like to thank to The Presidential Hospital of RSPAD Gatot Soebroto and all colleagues that support this study. We also thank Hasanuddin University and Prodia Education and Research Institute for their invaluable supports.

\section{References}

1. Hankey GJ. Long-term outcome after ischaemic stroke/transient ischaemic attack. Cerebrovasc Dis. 2003; 16 (Suppl 1): 14-9.

2. Guo Y, Li P, Guo Q, Shang K, Yan D, Du S, et al. Pathophysiology and biomarkers in acute ischemic stroke - a review. Trop J Pharm Res. 2013; 12: 1097-105.

3. Epstein CM, Wassermann EM. The Oxford Handbook of Transcranial Stimulation. New York: Oxford University Press; 2008.

4. Traversa R, Cicinelli P, Bassi A, Rossini PM, Bernardi G. Mapping of motor cortical reorganization after stroke. A brain stimulation study with focal magnetic pulses. Stroke. 1997; 28: 110-7.

5. Vanhoutte EK, Faber CG, van Nes SI, Jacobs BC, van Doorn PA, van Koningsveld R, et al. Modifying the Medical Research Council grading system through Rasch analyses. Brain. 2012; 135: 1639-49.

6. Renna R, Pilato F, Profice P, Della Marca G, Broccolini A, Morosetti $\mathrm{R}$, et al. Risk factor and etiology analysis of ischemic stroke in young adult patients. J Stroke Cerebrovasc Dis. 2014; 23: e221-7.

7. Streifler JY, den Hartog AG, Pan S, Pan H, Bulbulia R, Thomas DJ, et al. Ten-year risk of stroke in patients with previous cerebral infarction and the impact of carotid surgery in the Asymptomatic Carotid Surgery Trial. Int J Stroke. 2016; 11: 1020-7.

8. De Wit L, Theuns P, Dejaeger E, Devos S, Gantenbein AR, Kerckhofs $\mathrm{E}$, et al. Long-term impact of stroke on patients' health-related quality of life. Disabil Rehabil. 2016; 6: 1-6.

9. Lissens MA. Motor evoked potentials of the human diaphragm elicited through magnetic transcranial brain stimulation. J Neurol Sci. 1994; 124: 204-7.

10. Escudero JV, Sancho J, Bautista D, Escudero M, López-Trigo J. Prognostic value of motor evoked potential obtained by transcranial magnetic brain stimulation in motor function recovery in patients with acute ischemic stroke. Stroke. 1998; 29: 1854-9.

11. Jo Liepert J, Bauder H, Wolfgang HR, Miltner WH, Taub E, Weiller C. Treatment-induced cortical reorganization after stroke in humans. Stroke. 2000; 31: 1210-6. 